\title{
Síndrome de Wells con buena respuesta a la leflunomida: informe de un caso
}

\section{Wells syndrome with good response to leflunomide: case report}

\author{
Lya Magdalena Moneva-Leniz ${ }^{1 *}$, Eva María Sánchez-Martínez¹, Héctor Gegundez-Hernández¹, \\ Sara Ayala-Martínez ${ }^{2}$, Amparo Fuertes-Prosper ${ }^{1}$ y Almudena Mateu-Puchades ${ }^{1}$ \\ ${ }^{1}$ Servicio de Dermatología; ${ }^{2}$ Servicio de Anatomía Patológica. Hospital Universitario Doctor Peset de Valencia, Valencia, España
}

\begin{abstract}
Resumen
Se presenta el caso de una paciente de 56 años con celulitis eosinofilica (CE) vesículo-ampollosa que recurre tras un período asintomático de 18 años, sin desencadenante obvio, que responde al tratamiento con leflunomida, luego de la falla del tratamiento con hidroxicloroquina y metotrexato. La CE es una entidad infrecuente que puede relacionarse con neoplasias hematológicas. El tratamiento que ha mostrado ser más efectivo son los corticoides orales, pero son comunes las recaídas al suspenderlos. Se han descrito múltiples fármacos con respuestas variables como ahorradores de corticoides. Éste es el primer caso publicado de CE con respuesta favorable a la leflunomida.
\end{abstract}

Palabras clave: Sindrome de Wells. Celulitis esosinofilica. Leflunomida.

\begin{abstract}
We report the case of a 56-year-old woman with vesiculobullous eosinophilic cellulitis (EC) that relapsed after an asymptomatic period of 18 years without a recognizable trigger, which responded to leflunomide, after failure to treatment with hydroxychloroquine and methotrexate. EC is an infrequent entity that can be associated to hematological malignancies. Oral corticosteroids have proved to be the most effective treatment, but relapses are frequent after stopping them. Multiple corticoid-sparing agents have been used with diverse results. This is the first case report of EC with favorable response to leflunomide.
\end{abstract}

Key words: Wells syndrome. Eosinophilic cellulitis. Leflunomide.

\section{Introducción}

La celulitis eosinofílica (CE), también denominada síndrome de Wells, es una entidad poco frecuente caracterizada por lesiones cutáneas de morfología muy variada, que puede simular otras dermatosis más comunes como la celulitis bacteriana, por lo que el diagnóstico debe confirmarse con el estudio histopatológico de las lesiones. Los pacientes con CE suelen responder de modo favorable al tratamiento con corticoides orales, pero requieren fármacos ahorradores de corticoides para evitar los efectos adversos vinculados con su uso prolongado.

\section{Correspondencia:}

*Lya Magdalena Moneva-Leniz

E-mail: monevalenizlya@gmail.com
Disponible en internet: 13-05-2021 Med Cutan Iber Lat Am. 2021;49(1):51-54

www.MedicinaCutanealLA.com 0210-5187/@ 2020 Colegio Ibero Latinoamericano de Dermatología A.C. (CILAD). Publicado por Permanyer. Este es un artículo open access bajo la licencia CC BY-NC-ND (http://creativecommons.org/licenses/by-nc-nd/4.0/). 
La leflunomida es un compuesto inmunosupresor indicado para el tratamiento de la artritis psoriásica y artritis reumatoide, por lo que no es un fármaco de uso habitual en dermatología. Su administración requiere la vigilancia periódica clínica del paciente, junto con analíticas, dado que puede tener toxicidad en múltiples sistemas.

Se presenta el caso de una paciente con CE con buena respuesta al tratamiento con leflunomida.

\section{Caso clínico}

Paciente femenina de 56 años obesa e hipertensa bajo tratamiento con enalaprilo. Se la diagnosticó con CE 18 años antes y se la trató de forma exitosa con leflunomida por 15 meses. Tras suspender este fármaco, la paciente se mantuvo asintomática sin requerir la reintroducción de éste.

Consulta por lesiones muy pruriginosas en tronco y extremidades de dos semanas de evolución. La anamnesis es negativa para introducción reciente de fármacos, vacunación o consumo de AINE antes del inicio de los síntomas. La exploración revela pápulas excoriadas que simulan picaduras de distribución simétrica en brazos, piernas y dorso (Fig. 1).

A las tres semanas vuelve a consultar por empeoramiento clínico. Las lesiones han aumentado de tamaño y han llegado a formar placas edematosas, algunas con ulceración y exudado seroso. Llaman la atención vesículas en la periferia de algunas placas (Fig. 2). Se realiza una biopsia que revela un infiltrado inflamatorio superficial y profundo de distribución perivascular, perianexial e intersticial, en relación notoria con edema en dermis papilar y ulceración de la epidermis adyacente (Fig. 3A and B). El infiltrado es mixto y se integra con linfocitos, neutrófilos y abundantes eosinófilos (Fig. 3C). En algunas zonas, los eosinófilos rodean a los adipocitos (Fig. 3D).

Con el diagnóstico de CE se solicitan pruebas de laboratorio (hemograma, perfil bioquímico, proteinograma, inmunoelectroforesis de proteínas en sangre y orina) y de imagen (radiografía de tórax y mamografía) que muestran resultados dentro de los límites de la normalidad.

Se indica tratamiento con prednisona (PDN) a dosis de $60 \mathrm{mg} / \mathrm{día}$ en esquema descendente. Sin embargo, no es posible reducir la dosis por debajo de $30 \mathrm{mg} /$ día por la recaída clínica, con aparición de lesiones vesículo-ampollosas en tronco y manos, por lo que se decide añadir primero hidroxicloroquina $(400 \mathrm{mg} / \mathrm{d}) \mathrm{y}$ luego metotrexato (15 mg/día) durante tres meses, sin

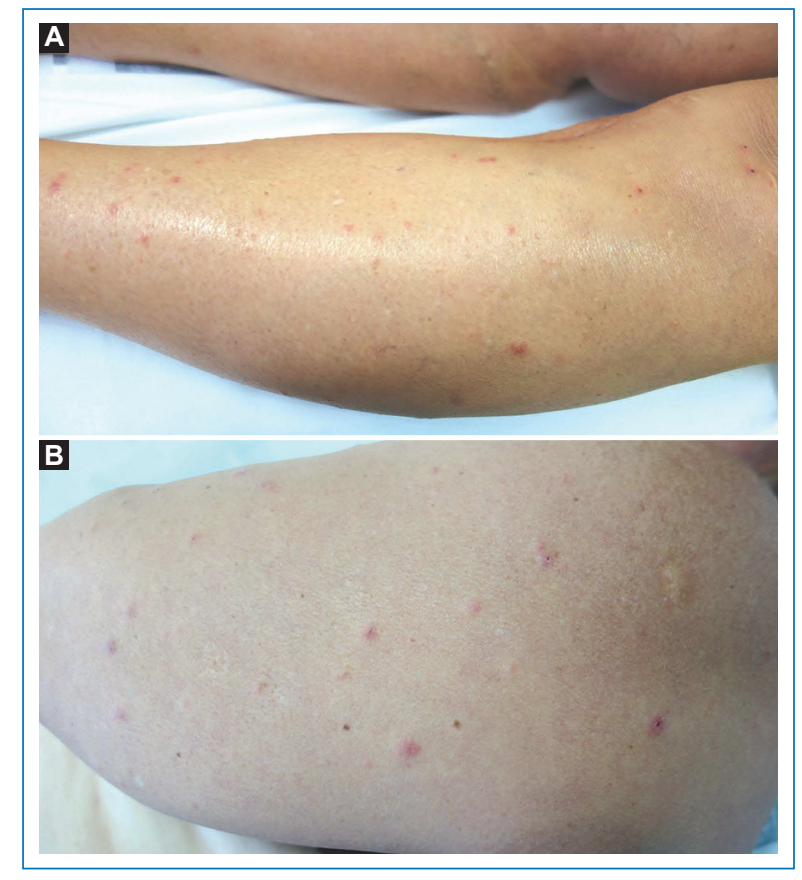

Figura 1. A-B: pápulas eritematosas que simulan picaduras en las extremidades.

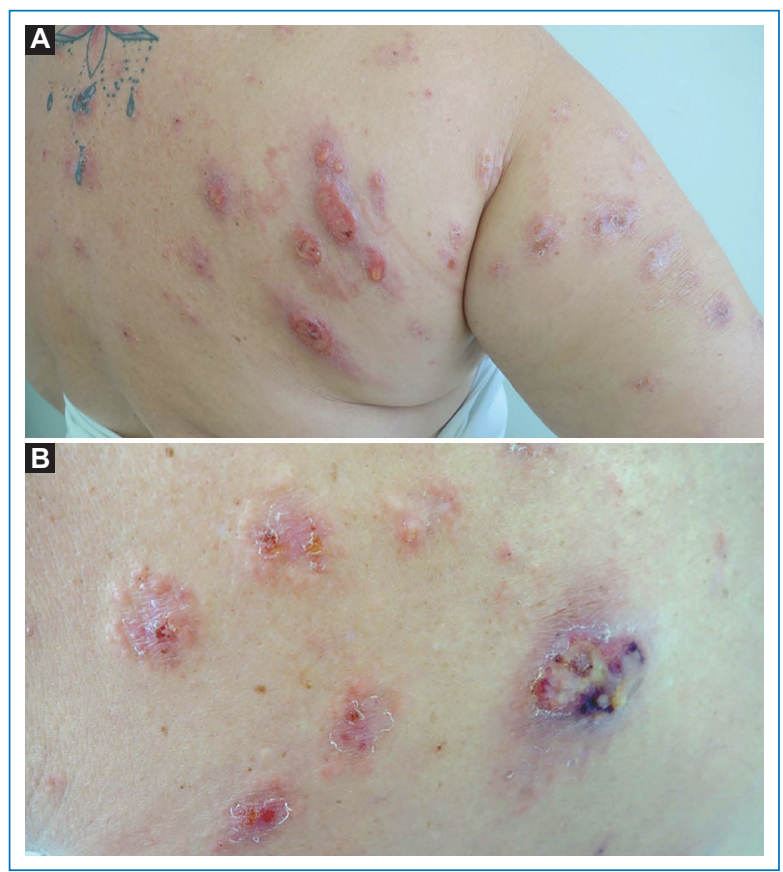

Figura 2. A-B: placas ulceradas en el dorso rodeadas por vesículas.

buen resultado. Se cambia el tratamiento a leflunomida (20 mg/día), con mejoría notable a los dos meses, por lo que se reduce la dosis de PDN a $5 \mathrm{mg} / \mathrm{d}$. En la 


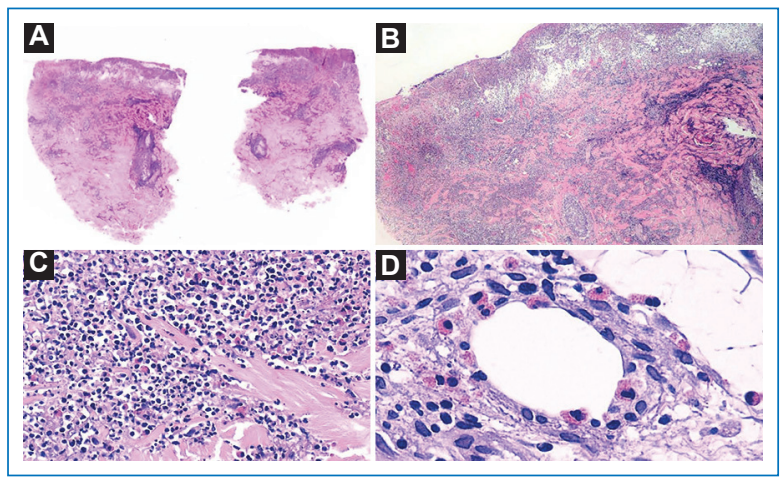

Figura 3. A: vista panorámica de una biopsia en sacabocados. Infiltrado inflamatorio denso de localización perivascular, perianexial e intersticial relacionado con edema marcado en dermis reticular y ulceración de la epidermis. B: el infiltrado intersticial diseca los haces de colágeno (HE 4x). C: el infiltrado es mixto y contiene abundantes eosinófilos (HE 20x). D: eosinófilos en derredor de un adipocito (HE 40x, ampliación).

actualidad, tras nueve meses de tratamiento con leflunomida y PDN (5 mg/d), la paciente se mantiene sin lesiones y no ha presentado efectos adversos secundarios a la leflunomida.

\section{Discusión}

La CE es una dermatosis eosinofílica que suele aparecer en adultos, sin propensión por ningún género 0 raza. Es controversial si es una enfermedad o un proceso reactivo de hipersensibilidad en respuesta a estímulos externos. Se ha sugerido que el aumento de linfocitos T CD4+CD7-productores de IL-5 (una citocina que favorece la producción, migración, activación y sobrevida de los eosinófilos) desempeña una función importante en su patogenia ${ }^{1}$. En realidad, Herout, et al, describieron un caso de CE con buena respuesta al mepolizumab, un anticuerpo humanizado anti-IL $5^{2}$.

Dentro de los desencadenantes descritos de la CE se hallan las infecciones, mordeduras o picaduras de insecto, infestación por parásitos (toxocara, ascaris, oncocercaria), fármacos ${ }^{3}$ (AINE, antibióticos, anestésicos, quimioterapia, tiazidas y fármacos anti-TNF- $\alpha$, entre otros) y vacunas ${ }^{4}$. Se ha relacionado con enfermedades hematológicas como leucemia linfática crónica ${ }^{5}$, leucemia mieloide crónica, linfoma no Hodgkin, tumores sólidos malignos, síndrome hipereosinofílico, granulomatosis eosinofílica con poliangeítis y eritema anular eosinofílico ${ }^{6}$.
La clínica cutánea es polimorfa y las lesiones pueden adoptar más de una morfología en un mismo paciente ${ }^{7}$. Éstas aparecen de forma aguda, son por lo general múltiples, típicamente dolorosas o pruriginosas y se localizan sobre todo en miembros, tronco y cara; pueden acompañarse de síntomas sistémicos como artralgias, malestar general, fiebre y alteraciones de laboratorio, como eosinofilia y elevación de VSG o PCR. Los brotes se resuelven en dos a seis semanas, pero las recurrencias son comunes, por lo que el cuadro puede persistir durante varios años.

Se han descrito múltiples variantes (las denominaciones varían según sea el autor), entre las que se encuentran la forma de placas, la vesículo-ampollosa ${ }^{3,8}$ y la pápulo-nodular ${ }^{9}$. En la primera, las placas son edematosas al principio y luego se vuelven más induradas. Pueden simular una celulitis bacteriana o una erisipela, o bien pueden adoptar un aspecto urticariforme o figurado, similar a entidades como el eritema fijo medicamentoso, el granuloma anular y el eritema anular centrífugo ${ }^{7}$.

El diagnóstico requiere confirmación con biopsia. Los hallazgos histopatológicos dependen de la edad de la lesión sometida a biopsia: a) en etapas tempranas existe un infiltrado intersticial, perivascular y perianexial denso compuesto por abundantes eosinófilos, que suele ocupar la dermis y el celular subcutáneo, con edema en dermis, algunas veces espongiosis y vesículas espongióticas intraepidérmicas o subepidérmicas con eosinófilos en su interior; y b) en fases más avanzadas disminuye el número de eosinófilos y pueden verse figuras en llama en la dermis, que más adelante son rodeadas por histiocitos para formar una empalizada ${ }^{10}$. Las figuras en llama son depósitos eosinófilos de proteínas provenientes de los gránulos de secreción de los eosinófilos, que se unen al colágeno. Éstos no son patognomónicos de la CE (ni un criterio necesario para su diagnóstico), ya que se han descrito también en parasitosis, picaduras/mordeduras de insecto, penfigoide y herpes gestacional, granulomatosis eosinofílica con poliangeítis, prurigo y toxicodermia ${ }^{11}$.

El tratamiento de la CE debe incluir siempre la identificación y el control de anomalías adjuntas, en especial de neoplasias hematológicas. Dada la evolución benigna y autolimitada de esta enfermedad, no sería siempre necesario su tratamiento por vía sistémica, sobre todo en niños, y si las lesiones son únicas y poco sintomáticas ${ }^{12}$. Los antihistamínicos orales pueden ayudar a disminuir el prurito acompañante. 
Dentro del tratamiento, los corticoides orales y tópicos son los más utilizados y son los únicos que han mostrado con claridad ser beneficiosos hasta ahora ${ }^{12}$. La dosis habitual de prednisona es de $1-2 \mathrm{mg} / \mathrm{kg} / \mathrm{día}$ en pauta descendente y es común que ocurran rebrotes al intentar reducir la dosis. Como ahorradores de corticoides, y en casos resistentes, se pueden administrar ciclosporina o dapsona. Otros tratamientos utilizados con anterioridad, pero sin eficacia demostrada por el escaso número de casos descritos, son azatioprina, antipalúdicos, griseofulvina, colquicina, doxiciclina, minociclina, tacrolimus oral o tópico, sulfasalazina, interferones $\alpha$ y $\gamma$, anti-TNF ${ }^{13}$, mepolizumab ${ }^{2}$ y PUVA.

\section{Conclusiones}

Éste es el caso de una mujer de 56 años con CE del tipo vesículo-ampolloso con buena respuesta a tratamiento con leflunomida. La CE es una dermatosis cutánea inflamatoria infrecuente con clínica polimorfa, cuyo diagnóstico requiere una correlación clínico-patológica. Tras su confirmación es necesario descartar neoplasias hematológicas adjuntas. El tratamiento regular incluye los corticoides orales, pero sus efectos adversos limitan su uso prolongado. Éste es el primer caso publicado de CE con respuesta favorable a la leflunomida. Aunque se requieren más datos sobre la efectividad y seguridad de la leflunomida como tratamiento de la $\mathrm{CE}$, puede considerarse en casos resistentes a otros tratamientos ahorradoras de corticoides.

\section{Conflicto de intereses}

Los autores declaran que no existe conflicto de intereses.

\section{Responsabiliades éticas}

Protección de personas y animales. Los autores declaran que los procedimientos seguidos se conformaron a las normas éticas del comité de experimentación humana responsable y de acuerdo con la Asociación Médica Mundial y la Declaración de Helsinki.

Confidencialidad de los datos. Los autores declaran que han seguido los protocolos de su centro de trabajo sobre la publicación de datos de pacientes.

Derecho a la privacidad y consentimiento informado. Los autores han obtenido el consentimiento informado de los pacientes $y / 0$ sujetos referidos en el artículo. Este documento obra en poder del autor de correspondencia.

\section{Bibliografía}

1. Yagi H, Tokura Y, Matsushita K, Hanaoka K, Furukawa F, Takigawa M. Wells' syndrome: a pathogenic role for circulating CD4+CD7- T cells expressing interleukin-5 mRNA. Br J Dermatol. 1997;136:918-923.

2. Herout S, Bauer WM, Schuster C, Stingl G. Eosinophilic cellulitis (Wells syndrome) successfully treated with mepolizumab. JAAD Case Rep. 2018:4:548-550.

3. Seçkin D, Demirhan B. Drugs and Wells' syndrome: a possible causal relationship? Int J Dermatol. 2001;40:138-140.

4. Koh KJ, Warren L, Moore L, James C, Thompson GN. Wells' syndrome following thiomersal-containing vaccinations. Australas J Dermatol. 2003;44:199-202.

5. Stuhr PM de OD, Vale ECS. Wells syndrome associated with chronic lymphocytic leukemia. An Bras Dermatol. 2015;90:571-574

6. Fujimoto N, Wakabayashi M, Kato T, Nishio C, Tanaka T. Wells syndrome associated with Churg-Strauss syndrome. Clin ExpDermatol. 2011;36:46-48.

7. Caputo R, Marzano AV, Vezzoli P, Lunardon L. Wells syndrome in adults and children: a report of 19 cases. Arch Dermatol. 2006;142:1157-161.

8. Kamiyama T, Watanabe $H$, Sueki $H$. Bullous eosinophilic cellulitis with subcorneal pustules. Indian J Dermatol Venereol Leprol. 2015;81:301-303.

9. Holme SA, McHenry P. Nodular presentation of eosinophilic cellulitis (Wells' syndrome). Clin Exp Dermatol. 2001 26:677-679.

10. Moossavi M, Mehregan DR. Wells' syndrome: a clinical and histopathologic review of seven cases. Int J Dermatol. 2003;42:62-67.

11. Wouters J, Waelkens E, Vandoninck S, Segaert S, van den Oord JJ. Mass spectrometry of flame figures. Acta Derm Venereol. 2015;95:734-735.

12. Räßler F, Lukács J, Elsner P. Treatment of eosinophilic cellulitis (Wells syndrome) - a systematic review. J Eur Acad Dermatol Venereol. 2016;30:1465-1479.

13. Sarin KY, Fiorentino D. Treatment of recalcitrant eosinophilic cellulitis with adalimumab. Arch Dermatol. 2012;148:990-992. 